\title{
МОДЕЛИРОВАНИЕ УПРАВЛЕНИЯ ПРОЦЕССОМ ЭКСТРУЗИОННОЙ ПЕРЕРАБОТКИ ЗЕРНОВОГО СЫРЬЯ ДЛЯ ПРОИЗВОДСТВА СУХИХ ЗАВТРАКОВ
}

Завальнюк И.П. 1

${ }^{1}$ Херсонский государственный аграрный университет, г. Херсон

E-mail: zavalnyukinna@rambler.ru

ORCID: 0000-0001-7691-1271

Copyright (C) 2014 by author and the journal "Automation technological and business - processes". This work is licensed under the Creative Commons Attribution International License (CC BY). http://creativecommons.org/licenses/by/4.0/

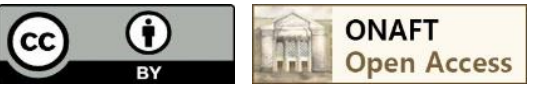

DOI: $10.15673 / 2312-3125$.

\begin{abstract}
Аннотация
В статье отмечена актуальность производтва высокопитательных сухих завтраков. Раскрыты особенности экструзионной обработки крахмалсодержащего зернового сырья. Уточнена математическая модель экструдера как диссипативного объекта. Предложена система управления экструдером с модальным регулятором для исключения внезапных перегрузок экструзионной установки.
\end{abstract}

\section{Abstract}

In article urgency production high-nourishing dry breakfasts is noted. The particularities extrusions processing of grain raw materials with high contain of starch are opened. The mathematical model of extruder as dissipative object is elaborated. The system of control of extruder with modal regulator for exception of the sudden overloading single-screw extrusion-cookers is offered.

Ключевые слова

Сухие завтраки, экструзия, диссипативные свойства, математическая модель, теплота диссипации, ультразвуковые механические колебания, интенсификация процесса, модальное управление.

\section{Введение}

Жизненный темп современного человека вызывает повышенный интерес к пище, которая не требует значительных временных затрат на ее приготовление, но при этом содержащей целый комплекс питательных элементов. Одним из таких продуктов питания являются сухие завтраки, которые согласно ДСТУ 2903:2005 по внешнему виду разделяют на воздушные зерна, крупяные палочки, крупяные батончики, крупяные подушечки, крупяные трубочки, фигурные изделия, хлебцы и сухарики [1]. Исходным сырьем при производстве сухих завтраков является зерновое сырье с высоким содержанием крахмала и без клейковины - кукуруза, рис, гречиха, а также манная крупа, отруби, зародыши пшеницы. В качестве добавок используются сушеные овощи и фрукты, различные специи и т.д.

Постановка задачи. Перспективной технологией, обеспечивающей существенную интенсификацию производственных процессов, является термовлагомеханическая обработка крахмалсодержащего зернового сырья, проводимая с использованием экструзионной техники. Экструзия является высокоэффективным, безотходным, кратковременным технологическим процессом, а экструдер многими исследователями рассматривается как 


\section{$\underline{2}$ АВТОМАТИЧНІ ТА АВТОМАТИЗОВАНІ СИСТЕМИ УПРАВЛІННЯ ТЕХНОЛОГІЧНИМИ ПРОЦЕСАМИ}

универсальный реактор [2]. Экструзионная обработка зернового сырья позволяет сохранить наиболее целебные и профилактические природные свойства зерна. Для получения готовых продуктов определенной формы, структуры и физико-химических свойств, а также продуктов высокого качества и требуемой консистенции необходимы определенные конструкционные особенности экструдера - количество шнеков и относительная длина экструзионной зоны, а также управление:

1. Температурным режимом экструзии с применением систем охлаждения и вентиляции;

2. Частотой вращения шнека, что определяет продолжительность и интенсивность воздействия на сырье;

3. Дозировкой сухого сырья и жидких компонентов в зону экструзии;

4. Режущим устройством.

При этом значимым фактором является неоднородность сырья, поскольку в процессе экструзионной переработки возможны изменения природы сырья, его состава и влажности.

Целесообразным является, учитывая свойства крахмалсодержащего зернового сырья и особенности технологии производства сухих завтраков, исследовать возможность построения системы управления с применением соответствующего метода управления современной теории автоматического управления. Данная система позволит исключить необходимость частой настройки технических параметров экструзионной линии, сохранить работу экструдера в требуемом режиме и обеспечит получение продукта с пористой структурой, стабильными размерами и требуемыми качественными свойствами.

Анализ последних публикаций. Как правило, для повышения эффективности процесса экструзии применяют две группы методов:

1. Конструкционные методы, позволяющие повысить производительность экструдеров путем изменения их конструктивных параметров;

2. Физические методы, интенсифицирующие работу экструдеров путем применения разных физических действий (механических колебаний) на экструдируемый материал, то есть за счет изменения структурных и реологических характеристик экструдата.

Известна полезная модель на автоматизированный экструдер [3], в основу которой поставлена задача получения нового технического результата, а именно: минимизация потерь сырья во время пуска экструдера и уменьшение затрат работы оператора.

Поставленная задача решается тем, что автоматизированный экструдер содержит цилиндр с гильзами и шнеком, который состоит из винтов, насаженных на вал, и шайб, которые размещены между винтами, конусный наконечник и термодатчик нагрева сырья, а на выходе из цилиндра установлена фильера. Шнек приводится в движение от электропривода. В соответствии с полезной моделью, дополнительно установлен термодатчик нагрева цилиндра, контактирующий с внешней поверхностью цилиндра и термодатчик нагрева воздуха, контактирующий с воздухом, окружающим автоматизированный экструдер. Для приема сигналов от термодатчика нагрева сырья, термодатчика нагрева цилиндра и термодатчика нагрева воздуха, и управления работой электродвигателя привода фильеры предусмотрен блок управления. Кроме того, имеется электродвигатель привода фильеры, передаточный механизм, состоящий из ведомого зубчатого колеса, закрепленного на фильере, и ведущего зубчатого колеса, соединенного с валом электродвигателя привода фильеры, штангу. Причем, электродвигатель привода фильеры устанавливается на цилиндре, электродвигатель повода фильеры устанавливается на штанге. Таким образом, в данной работе автор развивает конструкционные методы интенсификации экструзии.

Однако существуют и совершенствуются разработки в области управления экструзионными установками. Так, предложен способ автоматического управления линией производства экструдированных текстуратов [4], который предусматривает измерение расхода и влажности исходного сырья и экструдата, температуры продукта в предматричной зоне экструдера, а также частоты вращения регулируемого привода экструдера. Изобретение обеспечивает повышение качества готового продукта за счет усовершенствования схемы автоматического контроля и более точного регулирования технологических параметров процесса экструзии многокомпонентных смесей.

В процессе производства экструдированных текстуратов устанавливают заданное соотношение расходов компонентов воздействием на частоту вращения дозаторов и приводной звездочки ленточного транспортера, по расходу подготовленной исходной смеси устанавливают частоту вращения вала смесителя. В зависимости от влажности смеси осуществляют либо подачу теплоносителя, либо подачу воды в аппарат термовлажностной обработки, по расходу и влажности смеси после аппарата термовлажностной обработки устанавливают положение 


\section{2 АВТОМАТИЧНІ ТА АВТОМАТИЗОВАНІ СИСТЕМИ УПРАВЛІННЯ ТЕХНОЛОГІЧНИМИ ПРОЦЕСАМИ}

загрузочного бункера относительно корпуса экструдера, частоту вращения нагнетающего шнека и шнека экструдера.

По текущему значению влажности экструдированных текстуратов осуществляют многоуровневую коррекцию технологических режимов линии. Кроме того, возможно увеличение производительности линии путем синхронного изменения частоты вращения ленточного конвейера, смесителя и аппарата термовлажностной обработки. При отклонении температуры в сторону увеличения сначала уменьшают частоту вращения дорна и увеличивают зазор путем перемещения дорна относительно матрицы, а при отклонении температуры в сторону уменьшения сначала увеличивают частоту вращения дорна и уменьшают зазор путем перемещения дорна относительно матрицы.

Преимуществом рассмотренного способа автоматического управления экструзионной линией является учет такого возмущающего фактора как влажность сырья на входе в экструдер. Однако предлагаемые операции довольно длительны относительно динамично изменяющихся характеристик компонентов сырья и их состава в рецептуре производимых продуктов.

Кроме того, автор [5] отмечает, что существующие штатные системы автоматического управления процессом экструдирования биополимеров, реализуют, как правило, только функцию регулирования (стабилизации) тока нагрузки приводного электродвигателя экструдера и температуру его головки (матрицы). Практика показывает, что они не могут обеспечить устойчивое функционирование экструдера в энергетически эффективных режимах и, одновременно, высокие показатели качества готового продукта. Это обуславливает актуальность задачи совершенствования систем автоматического управления экструзией биополимеров. В данной работе отмечается что, в основу совершенствования должны быть положены современные достижения в теории автоматического управления, информационных технологиях и программно-техническом обеспечении систем автоматизации.

Цель статьи. Синтез способа управления пищевым экструдером, обеспечивающего постоянство требуемых показателей качества процесса переработки крахмалсодержащего зернового сырья и поддерживающего стабильность работы экструзионной установки в напряженном режиме функционирования, появление которого обуславливается неоднородностью природы сырья, его состава и влажности.

Решение задачи. Экструдер, с точки зрения теории динамических систем, можно рассматривать как диссипативный объект - неконсервативный объект, взаимодействующий с окружающей средой посредством выделения тепла из-за основного параметра экструзии - трения материала и расплава о стенки цилиндра и шнека.

Математическую модель экструдера с учетом его диссипативных свойств можно представить в виде [6]:

$$
\overrightarrow{\dot{z}}(t)=\left(A_{d}+A_{k}\right) \cdot \vec{z}(t)+B \cdot \vec{u}(t)=\left(\left(\begin{array}{cc}
0 & 0 \\
0 & -a_{1}
\end{array}\right)+\left(\begin{array}{cc}
0 & 1 \\
-a_{0} & 0
\end{array}\right)\right) \cdot \vec{z}(t)+B \cdot \vec{u}(t),
$$

где $A_{d}, A_{k}-$ матрицы диссипативной и консервативной части объекта соответственно; $a_{1}=\frac{1}{\rho \cdot c_{p} \cdot T} \cdot\left(\frac{2 \alpha}{h} \cdot \Delta T-q_{\text {Д }}\right), \quad a_{0}=-\frac{1}{\rho \cdot c_{p} \cdot T} \cdot\left(\frac{d q_{\text {Д }}}{d t}+C\right) ; \quad \rho \quad$ и $c_{p}-$ плотность и удельная теплоемкость перерабатываемого материала, $\kappa 2 / M^{3}$ и Джскг· $K$, соответственно; $h$ - глубина винтового канала экструдера, $M ; T-$ температура переработки, $K, \Delta T$ - разность температур перерабатываемого материала и стенок цилиндра (шнека), $K ; \alpha$ - коэффициент теплоотдачи, $B m / \mathrm{M}^{2} \cdot K ; q_{\text {д }}$ - тепловой поток, генерируемый за счет внутреннего трения перерабатываемой смеси, $B m / \mathrm{M}^{3} ; C$ - константа; $\vec{z}(t)$ - вектор переменных состояния, которые определяют координату потока материала; $u(t)$ - стандартная функция управления (как правило, изменение частоты вращения шнека экструдера); $B$ - матрица управления.

Тепловой поток, диссипирующий в единице объема перерабатываемой смеси за счет внутреннего трения, может быть определен, используя степенное уравнение Оствальд-де-Виля:

$$
q_{\text {д }}=\tau \cdot \dot{\gamma}=\eta \cdot \dot{\gamma}^{1+n},
$$

где $\tau$ - напряжение сдвига в материале, Па, $\dot{\gamma}-$ скорость сдвига (деформации), $c^{-1}, \eta-$ коэффициент консистенции материала, Па·c, $n$ - индекс течения материала. 


\section{2 АВТОМАТИЧНІ ТА АВТОМАТИЗОВАНІ СИСТЕМИ УПРАВЛІННЯ ТЕХНОЛОГІЧНИМИ ПРОЦЕСАМИ}

Коэффициент консистенции материала или эффективная вязкость смеси является одним из основных показателей структурно-механических свойств экструдатов. В работе [7] приведены результаты изучения зависимости реологических свойств (напряжения сдвига и эффективной вязкости) зерновой модельной смеси от начальной влажности и температуры.

Анализ полученных данных показал, что вязкость расплава пищевой смеси экспоненциально понижается с повышением температуры. Эффективная вязкость уменьшается и с увеличением скорости сдвига, что объясняется значительной хаотичностью расположения частиц в неподвижной среде и все большей ориентацией их в направлении течения под действием возрастающих сдвигающих усилий. Повышение исходной влажности продукта приводит к снижению вязкости и напряжения сдвига. Кроме того, вязкость при всех значениях начальной влажности уменьшается с повышением скорости сдвига.

В результате математической обработки было получено регрессионное уравнение эффективной вязкости расплава смеси от начальной влажности и температуры в предматричной зоне экструдера:

$$
\eta_{\text {эф }}=-1237,577+6,088 \cdot T+93,912 \cdot W-0,007 \cdot T^{2}+0,044 \cdot W^{2}-0,449 T \cdot W+0,0005 \cdot T^{2} \cdot W,
$$

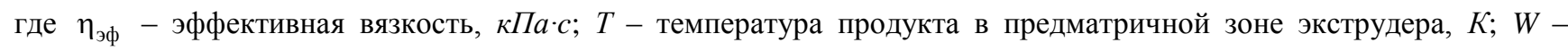
влажность экструдируемой смеси, \%.

Особенностью экструзионной переработки зернового крахмалсодержащего сырья является то, что при продавливании экструдата через отверстия фильеры возможно забивание отверстий за счет подсушивания массы и создания пробок, особенно если пищевая масса имеет густую консистенцию. Поскольку такие массы являются неньютоновскими жидкостями, для обеспечения продавливания через фильеры необходимо превысить некоторое начальное напряжение сдвига. С этой целью используют высокочастотные (ультразвуковые) механические колебания, накладываемые на шнек экструдера [8], что приводит к равномерному уплотнению материала, увеличению его пластичности и позволяет повысить ресурс эктсрузионного оборудования в несколько раз (таблица 1).

При совмещении гармонических сдвиговых колебаний, образующихся при интенсификации экструзии ультразвуком, и стационарного течения, деформация сдвига будет изменяться по следующему закону:

$$
\dot{\gamma}(t)=\dot{\gamma}_{0}(t)+\dot{\gamma}_{a} \cdot \sin \psi \cdot t
$$

где $\dot{\gamma}_{0}(t)$ - скорость сдвига в условиях установившегося сдвигового течения, $\dot{\gamma}_{a}-$ амплитуда сдвиговых деформаций, $\psi$ - частота колебаний.

Таким образом, варьируя параметрами ультразвука можно изменять характер течения материала, а параметром управления диссипативной частью экструдера может быть переменная $\dot{\gamma}(t)$.

Таблица 1 - Сравнительный анализ влияния амплитуды $A$ и частоты $\omega$ колебаний на состояние (поведение) экструдируемой смеси

\begin{tabular}{|c|l|}
\hline $\begin{array}{c}\text { Варьируемые параметры } \\
\text { колебаний }\end{array}$ & \multicolumn{1}{|c|}{ Анализ влияния колебаний } \\
\hline$\downarrow A$ и $\uparrow \omega$ & 1) уменьшается сцепление массы с поверхностью формующего элемента и \\
& ликвидируется налипание на него массы; \\
& 2) снижается сопротивление при прохождении массы в процессе формования; \\
& 3) уменьшается упругое последействие, которое обеспечивает сохранение формы \\
& жгута. \\
& Таким образом, появляется возможность управления свойствами поверхностного \\
& пласта. \\
\hline \multirow{1}{\uparrow}{$\downarrow$} & 1) достигается необходимое объемное разрушение структры массы и \\
& необходимая степень заполнения сечения формующего устройства; \\
& 2) обеспечивается ускорение релаксации напряжений; \\
& 3) увеличивается среднеинтегральная скорость течения. \\
& Следовательно, появляется возможность управления реологическими \\
& характеристиками в объеме массы. \\
\hline
\end{tabular}




\section{2 АВТОМАТИЧНІ ТА АВТОМАТИЗОВАНІ СИСТЕМИ УПРАВЛІННЯ ТЕХНОЛОГІЧНИМИ ПРОЦЕСАМИ}

Особенностью системы управления экструдером как диссипативным объектом является то, что стандартное управление $u(t)$ дополнено управлением диссипативной частью экструдера $u_{d}(t)$ - управление состоянием экструдируемой массы (рис. 1).

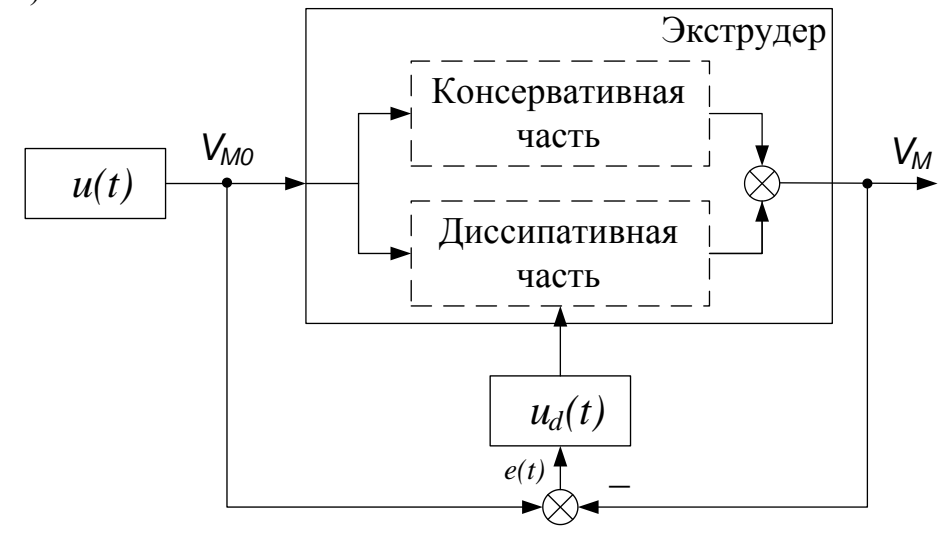

Рис. 1 - Структурная схема системы управления экструдером:

$V_{\text {M0 }}$ и $V_{\mathrm{M}}$ - заданная и текущая скорость экструдируемой массы.

Уточненную математическую модель экструдера с функцией управления диссипативной частью можно представить в виде:

$$
\overrightarrow{\dot{z}}(t)=\left[A_{d} \cdot \vec{z}(t)+B_{d} \cdot \vec{u}_{d}(t)\right]+A_{k} \cdot \vec{z}(t)+B \cdot \vec{u}(t),
$$

где $B_{d}$ - матрица управления диссипативной частью.

Целесообразно, для снижения случайной составляющей переходного процесса, использовать модальное управление, обеспечивающее заданное расположение корней характеристического уравнения на комплексной плоскости, т.е. восстанавливает их необходимое значение. Причем данный метод управления позволит исключить внезапных перегрузок экструзионной установки, возникающих из-за неоднородности перерабатываемого материала, а также из-за существующих требований к интенсификации процесса переработки зернового сырья.

Уравнение модального регулятора, реализующего ПИД закон регулирования [9], имеет вид:

$$
u_{d}(t)=\left(g_{0}-a_{0}\right) \cdot e(t)+K_{i} \int e(t) d t+\left(g_{1}-a_{1}\right) \cdot \frac{d e(t)}{d t},
$$

где $e(t)$ - отклонение текущего значения от заданного (ошибка выходного сигнала), $g_{1}$ и $g_{0}-$ коэффициенты матрицы объекта, соответствующие желаемому переходному процессу.

Коэффициенты передачи пропорциональной $K_{p}$, интегральной $K_{i}$ и дифференциальной $K_{d}$ составляющих ПИД-регулятора выбираются таким образом: $K_{d}=g_{1}-a_{1}, K_{p}=g_{0}-a_{0}, K_{i}$ - определяется по необходимой скорости протекания процесса.

Чтобы показать рациональность использования модального управления экструдером как диссипативным объектом, проведено имитационное моделирование разработанной системы управления в программе MATLAB. Рассмотрен способ производства чечевичных палочек [7] на экструдере А-80М (ООО «Алмаз», г. СанктПетербург, РФ). Способ позволяет получать комбинированные экструдированные продукты питания высокого качества из зернобобовых, богатых белком, что является одним из перспективных направлений производства «взорванных» изделий. В качестве сырья использовалась смесь компонентов в следующем соотношении, \% масс: $42 \ldots 44 \%$ чечевицы, 44,6..47,4\% рисовой крупы, 9,6..13,1\% подсолнечного шрота. Теплофизические свойства экструдируемой смеси следующие: плотность слоя $\rho=1440 \kappa 2 / \mathrm{M}^{3}$; удельная теплоемкость $c_{p}=1842$ Дж $/(\kappa 2 \cdot K)$.

Оптимальными параметрами обработки смеси на одношнековом экструдере являются: температура продукта перед матрицей $373 \ldots 393 K$, частота врашения шнека $1 \ldots 2 c^{-1}$ и давление в предматричной зоне экструдера $6 \ldots 10$ МПа. Данные параметры процесса обеспечивают полные и глубокие физико-химические изменения основных компонентов экструдируемого сырья. 


\section{$\underline{2}$ АВТОМАТИЧНІ ТА АВТОМАТИЗОВАНІ СИСТЕМИ УПРАВЛІННЯ ТЕХНОЛОГІЧНИМИ ПРОЦЕСАМИ}

Технические характеристики экструдера A-80M: диаметр шнека 80 мм; относительная длина (L/D) 15; мощность главного привода 45 кВт; число зон охлаждения 2; производительность на штатной матрице 220 кг/час; рабочее давление перед матрицей 10-15 МПа; расход воды на охлаждение (постоянный) 60 л/час.

Структурная схема моделирования в Simulink (рис. 2) полностью отражает математическую модель экструдера (3) как диссипативного объекта. Причем в схему введена подсистема Subsystem 1, в которой задаются технические характеристики экструдера и оптимальные параметры переработки экструдируемой смеси, а также функция изменения скорости сдвига (2), возникающая при использовании ультразвука в качестве интенсифицирующего воздействия. Кроме того, в схеме подсистемой Subsystem 2 задается изменение эффективной вязкости смеси, в зависимости от ее температуры и влажности согласно регрессионному уравнению (1). Причем для влажности, как возмущающего фактора, установлен аддитивный характер приведения возмущений:

$$
W(t)=W_{\text {ном }}+f_{W}(t)
$$

Составляющая $f_{W}(t)$ генерирована в форме случайного процесса с помощью блока генератора белого шума Band-Limited White Noice.

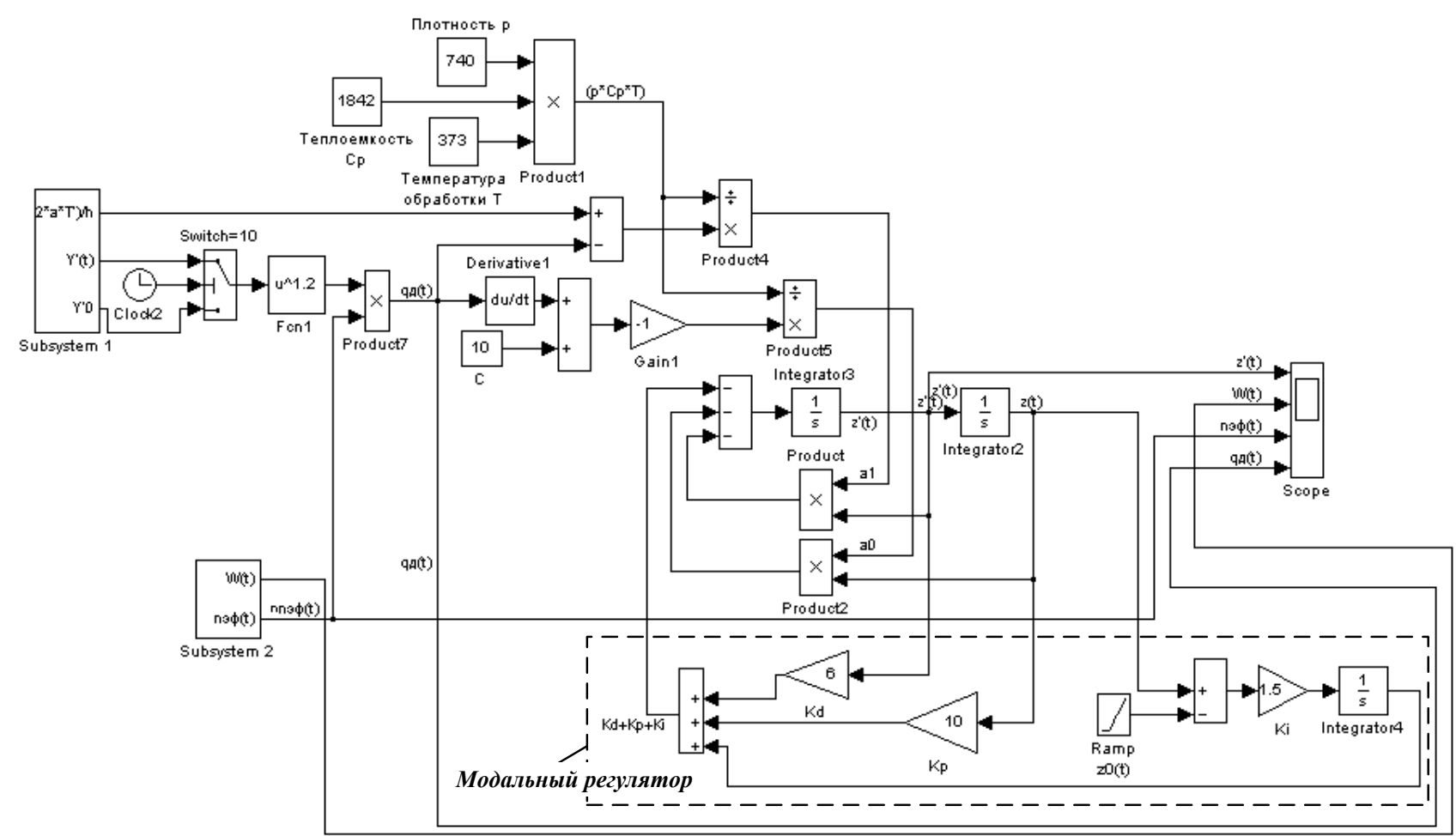

Рис. 2 - Схема моделирования управления экструдером как диссипативным объектом с модальным регулятором

Важным в схеме моделирования является наличие модального ПИД-регулятора, позволяющего поддерживать стабильность скорости потока материала при наличии возмущения и интенсифицирующего воздействия, что подтверждают результаты моделирования (рис. 3). 


\section{2 АВТОМАТИЧНІ ТА АВТОМАТИЗОВАНІ СИСТЕМИ УПРАВЛІННЯ ТЕХНОЛОГІЧНИМИ ПРОЦЕСАМИ}

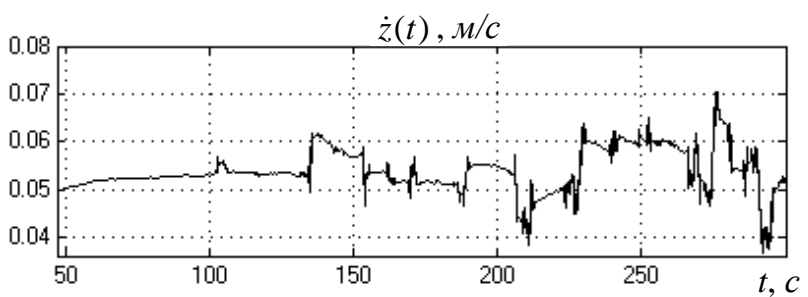

$W, \%$
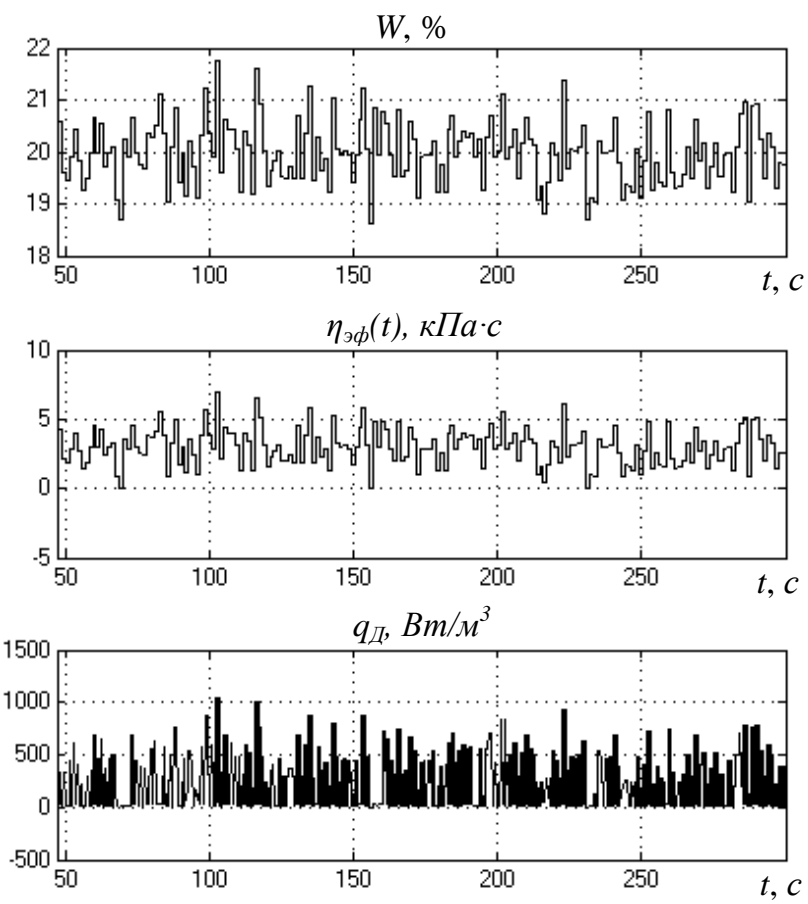

a)

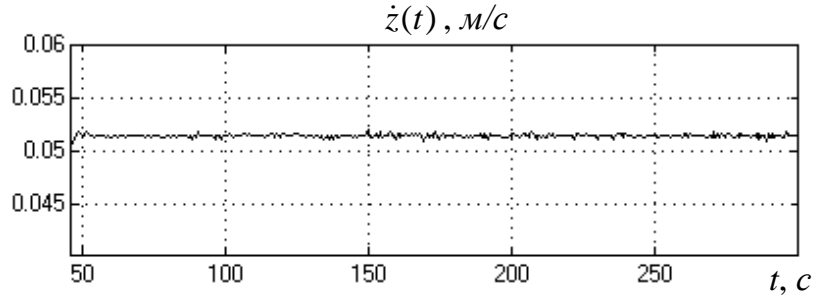

$W, \%$
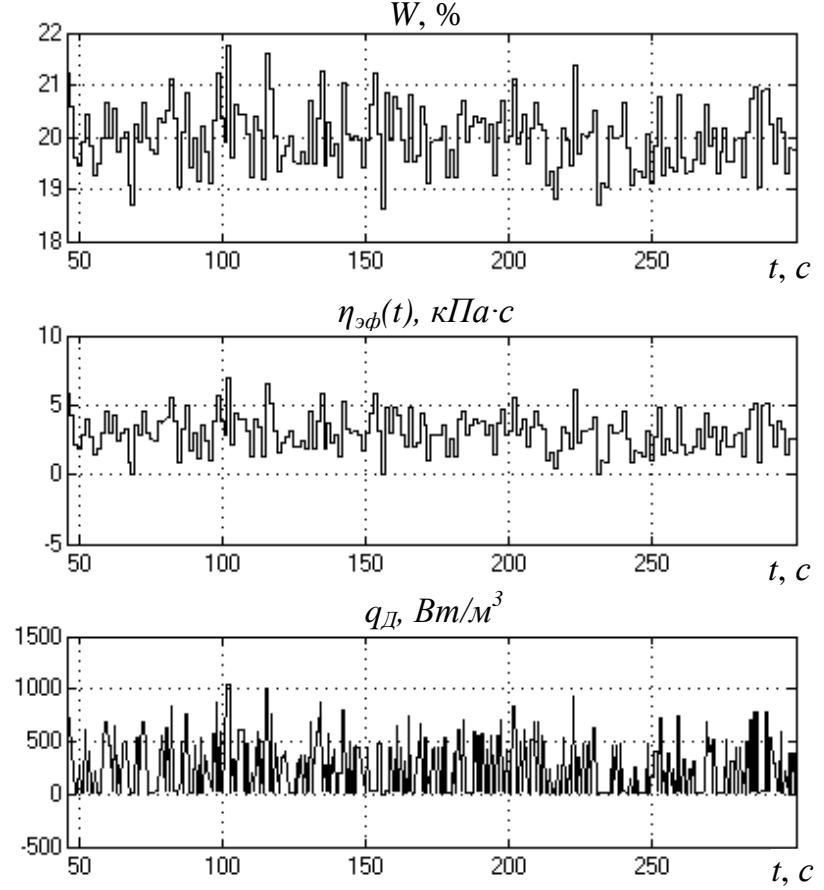

б)

Рис. 3 - Результаты моделирования процесса экструзии зернобобовых для производства чечевичных палочек с применением стандартного (а) и модального (б) управления экструдером: $\dot{z}(t)$ - скорость потока экструдата, $W(t)-$ влажность перерабатываемой смеси, $\eta_{\text {эф}}(t)$ - эффективная вязкость смеси, $q_{д}(t)$ - теплота диссипации

Сравнительный анализ результатов моделирования управления экструдером указывает на то, что применение модального управления по каналу диссипации исключает возможность возникновения пробки экструдата в предматричной зоне экструдера в случае изменения свойств перерабатываемого сырья, тем самым, сохраняя постоянство скорости материала при одинаковых условиях переработки.

\section{Выводы.}

1. Уточнена математическая модель экструдера как диссипативного объекта с целью установления закона управления процессом экструзии неоднородного по составу и свойствам зернового сырья;

2. Проведен сравнительный анализ влияния амплитуды и частоты высокочастотных механических колебаний на поведение экструдируемой смеси;

3. Доказана целесообразность использования модального управления по каналу диссипации в задаче поддержания постоянства показателей качества переходного процесса;

4. Подтверждена эффективность дополнения стандартного управления модальным управлением экструзией крахмалсодержащего зернового сырья в условиях интенсификации и непостоянства свойств сырья путем имитационного моделирования процесса экструзии.

\section{Литература}

1. ДСТУ 2903:2005. Концентрати харчові. Сніданки сухі. Загальні технічні умови: чинний від 2006-07-01. К.: Держспоживстандарт України, 2006. - 22 с. (Національний стандарт України). 


\section{$\underline{2}$ АВТОМАТИЧНІ ТА АВТОМАТИЗОВАНІ СИСТЕМИ УПРАВЛІННЯ ТЕХНОЛОГІЧНИМИ ПРОЦЕСАМИ}

2. Краус С.В. Совершенствование технологии экструзионной переработки крахмалсодержащего зернового сырья: автореф. дис. на соискание уч. степени д-ра техн. наук: спец. 05.18.01 «Технология обработки, хранения и переработки злаковых, бобовых культур, крупяных продуктов, плодоовощной продукции и виноградарства» / Сергей Викторович Краус; Моск. гос. ун-т пищ. пр-ств. - Москва, 2004. - 54 с;

3. Пат. 71903 Україна, МПК В29С 49/04, А23N 17/00, В29С 47/00. Екструдер автоматизований / Осипенко B.І., Некоз О.І., Філімонова Н.В., Філімонов С.О., Батраченко О.В., Скоробагатий В.О.; власник патенту Батраченко О.В. - № u 201201632; заявл. 14.02.2012; опубл. 25.07.2012, Бюл. №14;

4. Пат. 2412052 Российская Федерация, МПК В29С 47/92. Способ автоматического управления линией производства экструдированных текстуратов / Остриков А.Н., Василенко Л.И., Татаренков Е.А., Копылов М.В.; патентообладатель Государственное образовательное учреждение высшего профессионального образования "Воронежская государственная технологическая академия". - № 2009133500/05; заявл. 07.09.2009; опубл. 20.02.2011, Бюл. № 5;

5. Хобин В.А. Имитационная математическая модель процесса экструдирования биополимеров как объекта управления / В.А. Хобин, В.Б. Егоров // Наукові праці Одеської національної академії харчових технологій. - Одеса, 2010. - Вип.38. - Том 1. - С. 386-399;

6. Завальнюк И.П. Дослідження напружених режимів роботи дисипативних технологічних апаратів харчової та переробної промисловості / И.П. Завальнюк // XIX Міжнародна конференція 3 автоматичного управління (Автоматика-2012), м. Київ, 26-28 вересня 2012р.: матеріали конференції /Відп. за вип. А.П.Ладанюк. - К: НУХТ, 2012. - С.194-195;

7. Технология экструзионных продуктов / А.Н. Остриков, Г.О. Магомедов, Н.М. Дерканосова, В.Н. Василенко, О.В. Абрамов, К.В. Платов. - СПб: «Проспект Науки», 2006. - 202 с;

8. Хмелев В.Н. Ультразвуковые многофункциональные и специализированные аппараты для интенсификации технологических процессов в промышленности, сельском и домашнем хозяйстве [Текст] / В.Н. Хмелев, Г.В. Леонов, Р.В. Барсуков, С.Н. Цыганок, А.В. Шалунов. - Алт. гос. техн. ун-т, БТИ. Бийск: Изд-во Алт. гос. техн. ун-та, 2007. - 400 с;

9. Справочник по теории автоматического управления: [под ред. А.А. Красовского]. - М.: Наука. Гл. ред. физ.- мат. лит-ры, 1987.-712 с.

\section{References}

1. DSTU 2903: 2005. Concentrates food. Snack breakfasts. General specifications: valid from 2006-07-01. - K.: State Committee of Ukraine, 2006. - 22 p. (National Standard of Ukraine);

2. Kraus S.V. Improving the technology of extrusion processing of starch grain material: author. dis. on competition uch. the degree of dr. tehn. sciences: spec. 05.18.01 «Technology of processing, storage and processing of cereal, legumes, cereals, fruits and vegetables and wine»/ Sergey V. Kraus; Mosk. state. un-ty of food production. Moscow, 2004. - 54 p;

3. Pat. 71903 Ukraine, IPC B29C 49/04, A23N 17/00, B29C 47/00. Extruder automated / Osipenko V.I., Nekoz A.I., Filimonova N.V., Filimonov S.O., Batrachenko O.V., Skorobahatyy V.O.; patentee Batrachenko O.V. № u 201201632; appl. 14.02.2012; publ. 25.07.2012, Bull. №14;

4. Pat. 2412052 Russian Federation, IPC B29C 47/92. A method of automatic control production line of extruded texturates / Ostrikov A.N., Vasilenko L.I., Tatarenkov E.A., Kopylov M.V.; patentee State Educational Institution of Higher Professional Education «Voronezh State Technological Academy». - № 2009133500/05; appl. 07.09.2009; publ. 20.02.2011, Bull. № 5.;

5. Hobin V.A. Simulation mathematical model of the process of extrusion of biopolymers as a control object / V.A. Hobin, V.B. Egorov // Scientific work of Odessa National Academy of Food Technologies. - Odessa, 2010. Pub.38. - T. 1 - P. 386-399;

6. Zavalniuk I.P. Research intense modes of the dissipative technological devices and food processing industry / I.P. Zavalniuk // XIX International Conference of Automatic Control (Automation-2012), m. Kyiv, September 2628, 2012: conference materials / Answer. by vol. A.P. Ladanyuk. - K: NUFT, 2012. - P.194-195;

7. Technology of extrusion products / A.N. Ostrikov, G.O. Magomedov, N.M. Derkanosova, V.N. Vasilenko, O.V. Abramov, K.V. Platov. - St. Petersburg: "Prospect of Science", 2006. - 202 p.;

8. Khmelev V.N. Ultrasonic multifunctional and specialized devices for intensification of technological processes in industry, agriculture and household [Text] / V.N. Khmelev, G.V. Leonov, R.V. Barsukov, S.N. Ciganok, A.V. Varmints. - Alt. state. tehn. univ, BTI. - Bijsk: Publ. Altai Technical University, 2007. - 400 p;

9. Handbook of automatic control theory [ed. by A.A. Krasousky]. - M .: Nauka. Ch. Ed. Phys. mat. lit-ry, 1987.$712 \mathrm{p}$. 